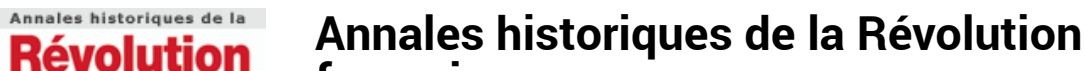

française française

340 | avril-juin 2005

Les arts et la révolution

\section{Toussaint-Louverture et l'indépendance d'Haïti}

\section{Bernard Gainot}

\section{(2) OpenEdition}

\section{Journals}

Édition électronique

URL : https://journals.openedition.org/ahrf/2024

DOI : 10.4000/ahrf.2024

ISSN : 1952-403X

Éditeur :

Armand Colin, Société des études robespierristes

Édition imprimée

Date de publication : 1 juin 2005

Pagination : 195-197

ISSN : 0003-4436

\section{Référence électronique}

Bernard Gainot, «Toussaint-Louverture et l'indépendance d'Haïti ». Annales historiques de la Révolution française [En ligne], 340 | avril-juin 2005, mis en ligne le 20 avril 2006, consulté le 22 avril 2022. URL : http://journals.openedition.org/ahrf/2024 ; DOI : https://doi.org/10.4000/ahrf.2024

Ce document a été généré automatiquement le 22 avril 2022.

Tous droits réservés 


\title{
Toussaint-Louverture et l'indépendance d'Haïti
}

\author{
Bernard Gainot
}

\section{RÉFÉRENCE}

Jacques DE CAUNA (éd.), Toussaint-Louverture et l'indépendance d'Haïti, Paris, Éditions Karthala - SFHOM, 2004, 299 p., ISBN : 2-84586-503-1.

1 Ce volume, centré autour de la figure de Toussaint-Louverture, est un recueil d'articles parus dans la Revue française d'histoire d'outre-mer, agrémenté d'une série de documents et d'inventaires, le tout présenté par Jacques de Cauna, éminent spécialiste de la société coloniale de Saint-Domingue, et notamment de la généalogie des habitations et des planteurs de la « perle des Antilles».

2 Force est de constater que le personnage est difficile à saisir, et a donné lieu à des interprétations fort divergentes. Rappelons pour mémoire que deux ouvrages ont fait date sur ce sujet. Tout d'abord, celui de C-R-L- James, qui voyait en Toussaint le guide d'un processus révolutionnaire émancipateur, le héros charismatique qui conduisit un soulèvement d'esclaves à la libération nationale (Les jacobins noirs). Pierre Pluchon, plus récemment, a dressé un portrait qui peut parfois apparaître comme iconoclaste, celui d'un chef surtout motivé par les intérêts de sa caste, celle des noirs libres, nostalgique d'une prospérité coloniale anéantie par la Révolution. Son projet, dès lors, est celui de restaurer la splendeur passée, mais au profit d'un ordre racial où l'ancien groupe des "noirs libres» aurait supplanté définitivement la caste des planteurs blancs (Un révolutionnaire d'Ancien Régime est le titre paradoxal de cette biographie). Disons, pour aller vite, que les éléments rassemblés ici par Jacques de Cauna, confortent plutôt cette version.

3 Mais, plus largement, et plus profondément, l'objectif est de mettre à distance l'icône, vénérée par la mémoire nationale haïtienne, pour retrouver, par une démarche historique diversifiée, un homme face à ses choix, pas toujours clairement perceptibles, 
et aussi dans sa dimension personnelle, familiale. Au terme du parcours, la complexité du personnage est ce qui ressort le plus, le secret dont il aimait à s'entourer n'ayant pas peu contribué à forger le mythe.

4 Démarche historique qui essaye d'explorer diverses facettes, plutôt que de proposer une nouvelle synthèse, provisoirement définitive. La première dimension est la dimension patrimoniale; l'auteur scrute ce que les diverses commémorations ont pu apporter sur le plan de la connaissance. Retenons particulièrement l'inventaire du catalogue de l'exposition présentée à l'Institut français de Port-au-Prince en 1953, pour le tricinquantenaire de l'indépendance d'Haïti: Toussaint-Louverture et l'indépendance d'Haïti. Nous y trouvons une richesse documentaire apte à nourrir le débat, aussi bien sur le plan factuel, que sur le plan iconographique ; que l'on songe en particulier aux incertitudes sur les traits véritables du général, à travers ses portraits officiels.

La deuxième dimension est la dimension proprement contextuelle; à travers des témoignages de contemporains, largement reproduits dans des articles qui sont autant de jalons pour mieux comprendre les choix du dirigeant à des moments historiques cruciaux pour le destin de la colonie. Retenons pour mémoire quatre d'entre eux, particulièrement significatifs, parce qu'ils nous interrogent sur la construction rétrospective du mythe. L'article de Marie-Antoinette Menier, Gabriel Debien et Jean Fouchard, de 1977 («Toussaint-Louverture avant 1789. Mythes et réalités») qui replace la carrière de Toussaint dans la société coloniale au sein du groupe des «noirs libres». Toussaint Breda, né esclave, est affranchi en 1776, ultérieurement propriétaire d'au moins treize esclaves. Ce qui n'est pas une originalité pour l'époque. L'article de David Geggus, de 1978 (« From his most Catholic Majesty to the godless Republic: the « volte-face» of Toussaint-Louverture and the ending of slavery in Saint-Domingue ») pose la question du ralliement de Toussaint, officier alors au service des Espagnols, à l'autorité du gouverneur général Laveaux au printemps 1794. La date de ce ralliement est le 6 mai 1794 : or, à cette date, compte tenu des communications et de l'état de guerre avec les Anglais, la colonie n'a pas connaissance officiellement du décret d'abolition de l'esclavage (la liberté générale) par la Convention le 4 février 1794. Le décret n'arrive officiellement à Saint-Domingue que le 8 juin. Il faut donc supposer d'autres motivations au futur général noir, motivations pour lesquelles la question de l'abolition de l'esclavage ne serait d'ailleurs pas absente, mais à chercher plutôt du côté de la politique suivie en la matière par les autorités espagnoles, et le comportement des autres chefs noirs adjoints de Toussaint, et eux aussi subordonnés à ces mêmes autorités. Ce serait donc dans un premier temps une défection plutôt qu'un ralliement déterminé; qui plus est, lorsque le ralliement s'opère, et contrairement à une présentation déformée de la situation militaire, les troupes de Laveaux ne sont pas en position désespérée face aux Anglais, mais sont passées à l'offensive dans la région du Port-de-Paix. Bien entendu, l'apport des troupes noires va se révéler décisif dans le renversement de situation opéré en l'an III.

Un bon nombre d'articles et de témoignages portent ensuite sur la situation critique des années 1798-1801. Pour cette période, un grand nombre de pistes restent encore à explorer. Jacques de Cauna présente intégralement le rapport du général Kerverseau au ministre de la Marine, publié par Pierre Pluchon en 1991 (« Toussaint-Louverture d'après le général de Kerverseau »). Ce rapport, très critique, dresse un portrait du général en chef de 1796 à 1801, puis il développe les moyens de conserver la colonie à la République. Selon Kerverseau, général républicain qui fut proche des Girondins, 
Toussaint prépare secrètement, et depuis sa promotion, une indépendance noire avec le soutien des Américains et des Anglais. S'il souhaite attirer l'attention des autorités françaises sur ce péril essentiellement stratégique, ce n'est pas pour prôner une restauration économique et sociale de l'Ancien Régime. La liberté générale doit impérativement être maintenue comme base d'une société respectueuse de l'égalité de toutes les couleurs. Tous les critiques du pouvoir absolu du gouverneur Toussaint ne sont donc pas des partisans forcenés du rétablissement de l'esclavage. Enfin, un autre article de Pierre Pluchon présente dans son contexte l'adresse de Toussaint du 20 décembre 1801, retrouvée aux Archives nationales par Monique Pouliquen, conservateur ("Toussaint-Louverture défie Bonaparte: l'adresse inédite du 20 décembre 1801 ", dans la Revue française d'histoire d'outre-mer, 1992). C'est d'abord la mystérieuse affaire du soulèvement des cultivateurs de la plaine du nord, en octobre 1801, à l'issue de laquelle le propre neveu et potentiel dauphin de Toussaint, le général Moyse Louverture, fut exécuté avec tous ses proches comme responsables du soulèvement. C'est ensuite la nouvelle des pourparlers de paix entre la France et l'Angleterre, qui rendent possibles la préparation de l'expédition militaire commandée par le général Leclerc. Le récit d'un témoin anonyme, parvenu en France, permet de mieux comprendre le sens de l'adresse, en rapport avec ces faits. Le gouverneur noir est décidé à mettre en état de défense l'ensemble de l'île, et donc à concentrer toutes ses forces pour organiser la résistance à l'expédition Leclerc. La rupture avec la métropole est donc consommée, et la marche vers l'indépendance rendue inéluctable. Toutefois, le lecteur non averti de l'ensemble du dossier peut facilement retenir l'idée que cette rupture est un acte délibéré, unilatéral, de Toussaint, faisant fi du climat hystérique que font alors régner à Paris les partisans du rétablissement du système esclavagiste. Ces derniers, abreuvant le gouvernement consulaire d'écrits et de conseils, n'ont pas été pour rien dans les décisions qui conduisirent à l'organisation d'une expédition manifestement "punitive». Ainsi, l'opinion du lecteur peut-elle être déformée, tant par le choix assumé de ne porter l'éclairage que sur Toussaint seul, que par la reproduction sans note critique de certains parti-pris de Pluchon, notamment lorsque ce dernier affirme que Toussaint est « l'exécuteur d'un projet farouchement hostile à la Révolution, ce système dictatorial, inégalitaire et raciste des jacobins blancs »; peutêtre aurait-il fallu rappeler que ce n'est pas tant « la Révolution » qui est en cause, que le régime de Bonaparte, et que les « jacobins » à Paris n'ont plus guère d'influence sur la conduite des affaires. Mais, une fois de plus, c'est un choix éditorial que nous prenons comme tel, avec les précautions d'usage.

7 La troisième et dernière dimension est une dimension généalogique, dans laquelle excelle l'auteur. Il s'efforce de suivre la descendance des deux fils de ToussaintLouverture, Placide et Isaac, depuis l'exil en France jusqu'à aujourd'hui (du moins pour la descendance de Placide Louverture). Est reproduit l'article de Michel Roussier de 1977 sur l'éducation des fils Louverture à Paris, à l'Institution nationale des colonies ("L'éducation des enfants de Toussaint-Louverture et l'Institution nationale des colonies»). Je peux toutefois regretter qu'il ne soit pas fait allusion à l'article que j'ai consacré à cette institution en 2000 dans la revue Dix-huitième siècle qui, sans contredire en rien l'article de Michel Roussier, apporte des éléments nouveaux, particulièrement sur le contexte politique dans lequel s'inscrit cette tentative tout à fait originale. Mais ce n'est là qu'un point de détail.

8 Jacques de Cauna met, avec ce volume, à la disposition des chercheurs sur l'histoire coloniale de la période révolutionnaire, mais aussi des étudiants qui préparent les 
concours d'enseignement, un instrument extrêmement précieux pour réfléchir sur le rôle d'un acteur historique de premier plan de l'âge des révolutions, mais aussi sur les rapports entre le mythe et l'histoire.

9 Ajoutons enfin que le volume est très richement illustré, à partir notamment des collections du docteur Chatillon, et de la collection personnelle de l'auteur. 